\title{
Sensitization to common allergens among patients with allergies in major Iranian cities: a systematic review and meta-analysis
}

\author{
Mozhgan Moghtaderi ${ }^{1,2}$, Saeed Hosseini Teshnizi ${ }^{3}$, Shirin Farjadian ${ }^{1,4}$ \\ ${ }^{1}$ Allergy Research Center, Shiraz University of Medical Sciences, Shiraz, Iran; ${ }^{2}$ Allergy Clinic of Ali-Asghar Hospital, Shiraz University of Medical \\ Sciences, Shiraz, Iran; ${ }^{3}$ Clinical Research Development Center of Children Hospital, Hormozgan University of Medical Sciences, Bandar Abbas, \\ Iran; ${ }^{4}$ Department of Immunology, Shiraz University of Medical Sciences, Shiraz, Iran
}

\begin{abstract}
Various allergens are implicated in the pathogenesis of allergic diseases in different regions. This study attempted to identify the most common allergens among patients with allergies based on the results of skin prick tests in different parts of Iran. Relevant studies conducted from 2000 to 2016 were identified from the MEDLINE database. Six common groups of allergen types, including animal, cockroach, food, fungus, house dust mite, and pollen were considered. Subgroup analysis was performed to determine the prevalence of each type of allergen. The Egger test was used to assess publication bias. We included 44 studies in this meta-analysis. The overall prevalence of positive skin test results for at least one allergen was estimated to be $59 \%$ in patients with allergies in various parts of Iran. The number of patients was 11,646 (56\% male and 44\% female), with a mean age of $17.46 \pm 11.12$ years. The most common allergen sources were pollen (47.0\%), mites (35.2\%), and food (15.3\%). The prevalence of sensitization to food and cockroach allergens among children was greater than among adults. Pollen is the most common allergen sensitization in cities of Iran with a warm and dry climate; however, sensitization to house dust mites is predominant in northern and southern coastal areas of Iran.
\end{abstract}

KEY WORDS: Allergens, Cockroaches, Fungi, Pollen, Hypersensitivity, Iran

\section{INTRODUCTION}

The term 'allergen' is used to describe any substance capable of stimulating production of immunoglobulin $\mathrm{E}$ (IgE) in a genetically predisposed individual [1]. The first allergens were identified in the 1980s. Thus far, many allergens have been reported by cross-

\section{Correspondence: Saeed Hosseini Teshniz}

Clinical Research Development Center of Children Hospital,

Hormozgan University of Medical Sciences, Bandar Abbas

7916839319, Iran

E-mail: Saeed.teshnizi@gmail.com

Received: Dec 25, 2016 / Accepted: Feb 5, 2017 / Published: Feb 5, 2017

This article is available from: http://e-epih.org/

(C) This is an open-access article distributed under the terms of the Creative Commons Attribution License (http://creativecommons.org/licenses/by/4.0/), which permits unrestricted use, distribution, and reproduction in any medium, provided the original work is properly cited.

(C) 2017, Korean Society of Epidemiology referencing databases, such as the Allergome and Pfam databases $[2,3]$. The most clinically important allergens are those related to animals, cockroaches, house dust mites (HDMs), foods, fungi, pollens, latex, and venom. Outdoors allergen sources are likely to be pollens, while HDMs are the most common source of indoor allergens [4].

Most animal allergens belong to mammals and birds, which are easily spread into the environment [5-7]. Sensitization to cockroaches is among the most common factors contributing to increased asthma morbidity. It appears that genetic background may also play a role in susceptibility to cockroach allergens [8,9]. HDMs are an important factor that may exacerbate different types of allergic diseases in predisposed individuals. These small arthropods live in close contact with humans and are found in large numbers in beds, sofas, carpets, and furniture. The growth of mites is inhibited in environments with low humidity and extreme temperatures $[10,11]$. Food-allergic patients, mainly children, show a higher sensitization to the ingestion of eggs, cow's milk, nuts, soy, seafood, and wheat. However, allergies to various fruits and vegetables have also been 
reported, with lower frequencies $[12,13]$. Fungi are considered to be a primarily outdoor source of allergens, but the Aspergillus species can be found inside in warm and humid places [14,15]. Pollen allergens arise from the pollination processes of trees, weeds, and grass species. In many regions around the world, trees compromise the most clinically relevant source of allergenic pollens. Weeds can be defined as unwanted plants, and grasses are ubiquitous plants, which account for over 95\% of allergies [16-18].

As a diagnostic test, the skin prick test (SPT) is routinely used to detect IgE-mediated sensitization to specific allergens. The SPT procedure is performed using standard commercial extracts of allergens administered with a sterile lancet on the forearm. The results of the skin test are examined after 15 minutes and considered positive when the wheal is $3 \mathrm{~mm}$ greater in diameter than the negative control (saline) [19].

Iran is the second largest country in the Middle East and 18th largest in the world, with a total area of $1,648,195 \mathrm{~km}^{2}$ and a population of around 78.4 million in 2016. Iran has a hot and dry climate in most areas, but there is high humidity on the northern coastal area along the Caspian Sea, and the southern coastal area adjacent along the Persian Gulf. Iran is divided into 31 provinces. Tehran (including Karaj), Mashhad, Isfahan, Tabriz, Shiraz, and Ahvaz are the five largest cities.

This systematic review and meta-analysis was designed to determine the prevalence of sensitization to common allergens using the published data on allergen sensitization in different regions of Iran.

\section{MATERIALS AND METHODS}

\section{Search method}

The literature and reference searches were performed in March 2016. The present study was designed based on the guidelines for the Preferred Reporting Items for Systematic Reviews and MetaAnalyses (PRISMA) statement [20]. Persian-language and Englishlanguage databases were accessed and searched for articles that were published in the period from January 2000 to March 2016 published from January 2000 to March 2016. Articles from the MEDLINE database, as well as Iranian databases (Magiran, Iran Medex) and international databases (PubMed, ProQuest, Scopus SID, Google Scholar, and Science Direct) were identified.

The databases were searched based on the following keywords: (1) [“allergens" AND "Iran”], (2) ["asthma” AND "Iran”], (3) [“allergic rhinitis" AND "Iran”], (4) ["atopic dermatitis" AND "Iran”] and ["skin test" AND "Iran"]. The reference sections of all included studies were also utilized to identify additional relevant articles.

\section{Data extraction}

To assess studies for inclusion in the meta-analysis, two authors (MM and SHT) separately screened the title and abstract and then reviewed the full texts of studies identified in the literature review. A 93\% match in the assessment of article inclusion was obtained between the two authors, which showed that there was a high agreement between authors. Any disagreements were resolved by con- sultation with a third author (SF) for the final decision.

To assess the quality of studies included in the meta-analysis, we selected six items from the Strengthening of the Reporting of Observational Studies in Epidemiology (STROBE) checklist and assessed studies for whether they: (1) clearly defined the outcome (i.e., allergen), (2) gave the eligibility criteria, (3) presented key elements of study design, (4) reported numbers of outcome events, (5) explained how the study sample was determined, and (6) described the setting, locations, and relevant dates of the study. The studies that fulfilled all criteria were classified as high quality. The studies that did not fulfill one of the criteria were classified as intermediate quality, and the studies that did not fulfill more than one of the criteria were classified as low quality.

We extracted the following information: the name of the first author, the publication year of the article, the province in which the study was performed, the type of study, the sample size of the study, and the age and sex of the patients. The rate of sensitization to at least one of the allergens, including those of animals, cockroaches, food, fungi, HDMs, and pollen, was also reported.

\section{Inclusion and exclusion criteria}

Studies were included in this meta-analysis if the following criteria were met: (1) the study was conducted between January 2000 and March 2016; (2) it provided sufficient information to estimate the prevalence of allergens, with standard errors (SEs) and confidence intervals (CIs); (3) it reported descriptive statistics of age and sex and the prevalence of at least one of the allergens out of those of animals, cockroaches, food, fungi, HDMs, and pollen in terms of types of characteristics; (4) it was a cross-sectional study; (5) it was published in Persian or English; and (6) the study participants had a primary diagnosis for an allergy, including asthma, allergic rhinitis, atopic dermatitis, food allergy, chronic sinusitis, or chronic urticaria.

Studies were excluded if: (1) the study was a randomized controlled trial, a case report, or an animal study; (2) the article did not offer sufficient data to calculate the estimated prevalence of the allergen; (3) the study reported venom or latex allergens (these studies are addressed in the discussion); or (4) the article overlapped with another that had been identified.

\section{Statistical analysis}

We present the effect size for each study as prevalence $(\mathrm{P})$. The SE of each study was calculated based on a binomial distribution. The results for each study and the pooled outcomes were displayed as forest plots (reported as an effect estimate with the 95\% CI). To assess heterogeneity among studies, the I-square statistic $\left(\mathrm{I}^{2}\right)$ (with $25 \%$ designated as low, $50 \%$ as medium, and $75 \%$ as high heterogeneity) as well as the results of the Cochran Q-test (with $\mathrm{p}<0.1$ considered to be statistically significant) were also reported. Subgroup meta-analysis was used to compare the prevalence of allergens based on the results of SPTs among different age groups. The Egger test was used to evaluate the publication bias, plotting the regression line between the precision of the studies (the independ- 
ent variable) and the standardized effect (the dependent variable). Stata version 11 (StataCorp., College Station, TX, USA) was used for data analysis.

\section{RESULTS}

\section{Literature search}

Initial searches of databases identified 352 articles and an additional six studies through hand searches and expert suggestions, giving a total of 358 articles that were screened. Out of these, 156 were chosen for reading of the full text and 44 were included in this meta-analysis. Figure 1 shows our article selection process according to the PRISMA flowchart.

\section{Characteristics of the studies}

All studies reported in this systematic review and meta-analysis were cross-sectional studies. After all inclusion and exclusion criteria had been evaluated, 44 studies containing 11,646 patients (56\% male and $44 \%$ female) were included in the meta-analysis [21-64]. The mean age of the patients was 17.7 years (95\% CI, 14.0 to 21.4 years). Of the 44 selected research studies, animal allergens were examined in 15 , cockroach allergens in 17 , food allergens in 21 , fungal allergens in $23, \mathrm{HDM}$ allergens in 25 , and pollen allergens in 22. The basic characteristics of the published studies are presented in Table 1.

The prevalence of various animal allergens among patients with allergies is shown in Figure 2A. These patients most often showed sensitization to animal dander (33\%). Other types of animal allergen showed a similar prevalence rate (about $18 \%$ ).

The prevalence of sensitization to food allergens is shown in Figure $2 \mathrm{~B}$. A positive skin test result for cow's milk, eggs, and nuts was obtained in 16,18 , and $15 \%$ of cases, respectively. In addition, overall sensitization to food allergens was $15 \%$.

As shown in Figure 2C, the most common fungal allergen was Candida (27\%), followed by Cladosporium (26\%), Alternaria (20\%), and Aspergillus (17\%).

Sensitization to HDMs was reported in $33 \%$ of cases, as shown in Figure 2D. No significant differences were found between the prevalence of Dermatophagoides pteronyssinus and Dermatophagoides farina sensitization in patients with allergies.

As shown in Figure 2E, the overall sensitization to pollen allergens was $45 \%$ in patients with allergies. Sensitization to weed allergens had the highest prevalence (54\%), followed by grass ( $42 \%)$, and trees (40\%).

The estimated frequency of common allergens in major cities of Iran is shown in Table 2 according to the results of the subgroup analysis. The highest sensitization to animal allergens and HDMs was detected in coastal cities. The highest prevalence of cockroach allergen sensitization was reported in Shiraz and Ahvaz. Sensitization to different food allergens was approximately the same between major cities. The highest prevalence of fungal allergen sensitization was in Tehran. The frequency of sensitization to pollen was highest in Ahvaz, Mashhad, and Shiraz, in that order (Table 2).

The age distribution of patients with positive SPT results for common allergens is given in Table 3. Cockroach allergen sensitization was more prevalent in children $\leq 16$ years old than in adults. The prevalence of sensitization to food allergens was also significantly higher in patients younger than 5 years old compared to those of older age, at $26.2 \%$ (95\% CI, 22.8 to $29.7 \%$ ). However, the prevalence of sensitization to other allergens such as animal, fungal, HDM, and pollen was more prevalent among adults (Table 3).

The results of the Egger test for each of subgroup of allergens showed that there was no publication bias among the studies ( $\mathrm{p}>$ $0.05)$.
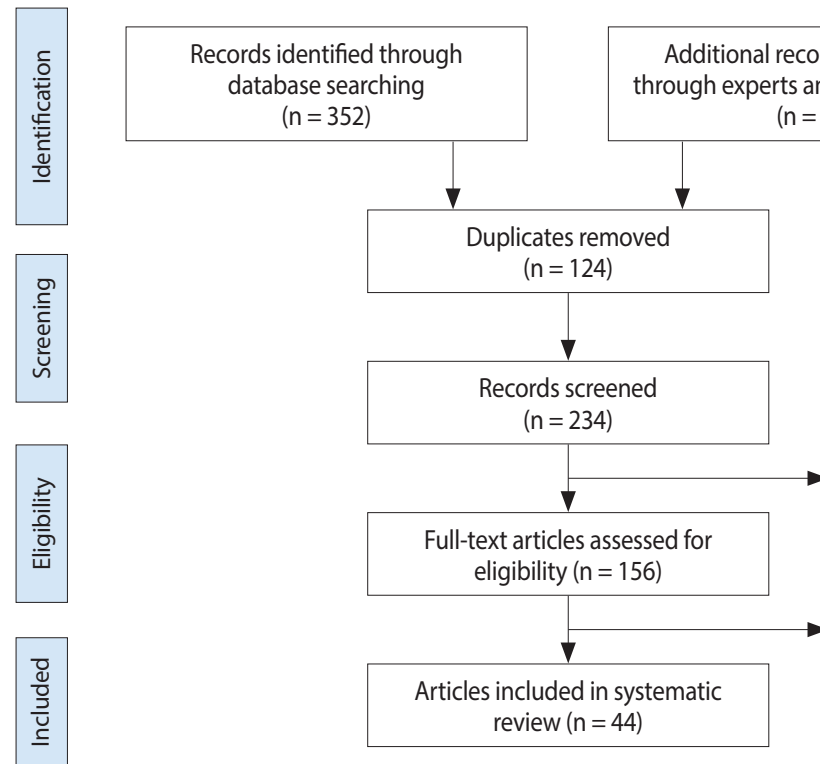

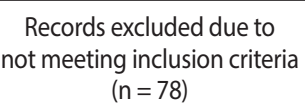

Full-text articles $(n=112)$

- Excluded $(n=63)$

- Not relevant $(n=27)$

- Context $(n=22)$

Figure 1. Flow diagram for study inclusion in the systematic review and meta-analysis. 
Table 1. Characteristics of studies included in the meta-analysis of the prevalence of sensitization to common allergens in Iran

\begin{tabular}{|c|c|c|c|c|c|c|c|c|c|c|}
\hline Authors (publication year) & City & $\begin{array}{c}\text { No. of } \\
\text { patients }\end{array}$ & $\begin{array}{c}\text { Age } \\
\text { (mean) }\end{array}$ & $\begin{array}{c}\text { Male } \\
(\%)\end{array}$ & $\begin{array}{c}\text { Animal } \\
(\%)\end{array}$ & $\begin{array}{c}\text { Cock- } \\
\text { roach } \\
(\%)\end{array}$ & $\begin{array}{c}\text { Food } \\
(\%)\end{array}$ & $\begin{array}{c}\text { Fungal } \\
(\%)\end{array}$ & $\begin{array}{c}\text { HDM } \\
(\%)\end{array}$ & $\begin{array}{c}\text { Pollen } \\
\text { (\%) }\end{array}$ \\
\hline Abdollahi-Fakhim et al. (2014) [21] & Tabriz & 106 & 6.5 & 50 & 12 & NR & 26 & 10 & 23 & 35 \\
\hline Ahanchian et al. (2016) [22] & Mashhad & 371 & 5.3 & 54 & NR & NR & 100 & NR & NR & NR \\
\hline Ahmadiafshar et al. (2008) [23] & Zanjan & 200 & 28.2 & 44 & 12 & 15 & 9 & 12 & 16 & 41 \\
\hline Akbari Hedayat et al. (2000) [24] & Isfahan & 1,077 & NR & NR & NR & 20 & NR & 37 & 35 & 48 \\
\hline Mokhtari Amirmajdi et al. (2011) [25] & Mashhad & 58 & 29.8 & 45 & NR & NR & NR & 53 & NR & NR \\
\hline Arshi et al. (2010) [26] & Tehran & 245 & 26.4 & 48 & NR & NR & NR & 50 & 64 & 92 \\
\hline Assarehzadegan et al. (2013) [27] & Ahvaz & 299 & 32.0 & 52 & NR & 30 & NR & 24 & 43 & 89 \\
\hline Behmanesh et al. (2010) [28] & Mashhad & 133 & 7.8 & 62 & 9 & 6 & NR & NR & 19 & 57 \\
\hline Bemanian et al. (2012) [29] & Yazd & 95 & 22.7 & 55 & NR & 13 & NR & NR & 8 & NR \\
\hline Bonyadi et al. (2014) [30] & Tabriz & 90 & 29.0 & 44 & NR & NR & NR & 24 & NR & NR \\
\hline Farajzadeh et al. (2010) [31] & Kerman & 51 & $<5.0$ & 63 & NR & NR & 62 & NR & NR & NR \\
\hline Farhoudi et al. (2002) [32] & Tehran & 100 & 6.2 & 68 & 2 & 29 & 10 & NR & 31 & 33 \\
\hline Farhoudi et al. (2005) [33] & Tehran & 226 & 13.5 & 55 & NR & 25 & NR & NR & 19 & 62 \\
\hline Farjadian et al. (2012) [34] & Shiraz & 79 & 3.0 & 56 & NR & NR & 15 & NR & NR & NR \\
\hline Farrokhi et al. (2015) [35] & Bushehr & 743 & 27.2 & 53 & 78 & NR & NR & 82 & 88 & 77 \\
\hline Fazlollahi et al. (2007) [36] & Tehran & 250 & 11.7 & 52 & NR & NR & 14 & NR & NR & NR \\
\hline Fereidouni et al. (2009) [37] & Mashhad & 306 & 25.6 & 47 & NR & 21 & NR & 8 & 20 & 77 \\
\hline Fouladseresht et al. (2014) [38] & Kerman & 157 & NR & 49 & 7 & 12 & 21 & 6 & 8 & 22 \\
\hline Ghaffari et al. (2012) [39] & Sari & 375 & 13.5 & 34 & 7 & 15 & NR & 3 & 25 & 4 \\
\hline Hosseini et al. (2014) [40] & Tehran & 313 & 5.7 & 62 & 15 & 18 & 21 & 26 & 22 & 26 \\
\hline Kashef et al. (2003) [41] & Shiraz & 212 & 18.2 & 50 & NR & NR & NR & 8 & 22 & 92 \\
\hline Khazaei et al. (2003) [42] & Zahedan & 1,285 & $2.0-79.0$ & 43 & 70 & NR & 30 & 65 & 89 & 43 \\
\hline Khazaei et al. (2015) [43] & Zahedan & 478 & $15.0-70.0$ & 58 & 26 & 25 & NR & 53 & 51 & 30 \\
\hline Khosravi et al. (2009) [44] & Tehran & 180 & NR & NR & NR & NR & NR & 54 & NR & NR \\
\hline Mahram et al. (2013) [45] & Qazvin & 163 & 24.6 & 42 & 25 & NR & NR & 26 & 20 & 58 \\
\hline Moghtaderi et al. (2010) [46] & Shiraz & 230 & 6.3 & 76 & NR & NR & NR & 10 & NR & NR \\
\hline Moghtaderi et al. (2012) [47] & Shiraz & 90 & 1.6 & 53 & NR & NR & 40 & NR & NR & NR \\
\hline Moghtaderi et al. (2015) [48] & Shiraz & 50 & 32.0 & 20 & NR & NR & 58 & NR & NR & NR \\
\hline Moghtaderi et al. (2015) [49] & Shiraz & 656 & 27.6 & 44 & 16 & 30 & NR & 16 & 34 & 64 \\
\hline Moghtaderi et al. (2015) [50] & Shiraz & 200 & 21.1 & 35 & 36 & NR & NR & NR & NR & NR \\
\hline Mohammadi et al. (2008) [51] & Tehran & 206 & 18.0 & 52 & NR & NR & 5 & NR & NR & NR \\
\hline Mohammadzadeh et al. (2012) [52] & Babol & 180 & 6.8 & 52 & NR & NR & NR & NR & 61 & NR \\
\hline Movahedi et al. (2000) [53] & Tehran & 400 & 19.0 & 52 & NR & NR & NR & NR & NR & 57 \\
\hline Nabavi et al. (2010) [54] & Semnan & 298 & 10.0 & NR & NR & NR & 30 & NR & NR & NR \\
\hline Nabavi et al. (2010) [55] & Semnan & 220 & $<18.0$ & 60 & NR & NR & NR & 35 & NR & NR \\
\hline Nabavizadeh et al. (2013) [56] & Yasuj & 184 & 23.7 & 65 & 23 & 35 & 33 & 48 & 8 & 37 \\
\hline Onsori et al. (2016) [57] & Tehran & 282 & 25.0 & 40 & NR & NR & 31 & NR & NR & NR \\
\hline Pourpak et al. (2003) [58] & Tehran & 190 & 4.8 & 58 & NR & NR & 53 & NR & NR & NR \\
\hline Pourpak et al. (2004) [59] & Tehran & 119 & $0.1-12.0$ & NR & NR & NR & 44 & NR & NR & NR \\
\hline Safari et al. (2009) [60] & Shiraz & 92 & 2.7 & 64 & 18 & 25 & 19 & 10 & 27 & 27 \\
\hline Salehi et al. (2009) [61] & Tehran & 100 & 2.7 & 71 & NR & NR & 39 & NR & NR & NR \\
\hline Shakurnia et al. (2014) [62] & Ahvaz & 407 & 31.5 & 52 & NR & 32 & NR & NR & 23 & NR \\
\hline Shakurnia et al. (2013) [63] & Ahvaz & 111 & 30.7 & 51 & NR & 38 & NR & 32 & 41 & 86 \\
\hline Varasteh et al. (2007) [64] & Mashhad & 38 & 38.0 & NR & NR & NR & 70 & NR & NR & NR \\
\hline
\end{tabular}

HDM, house dust mite; NR, not reported. 


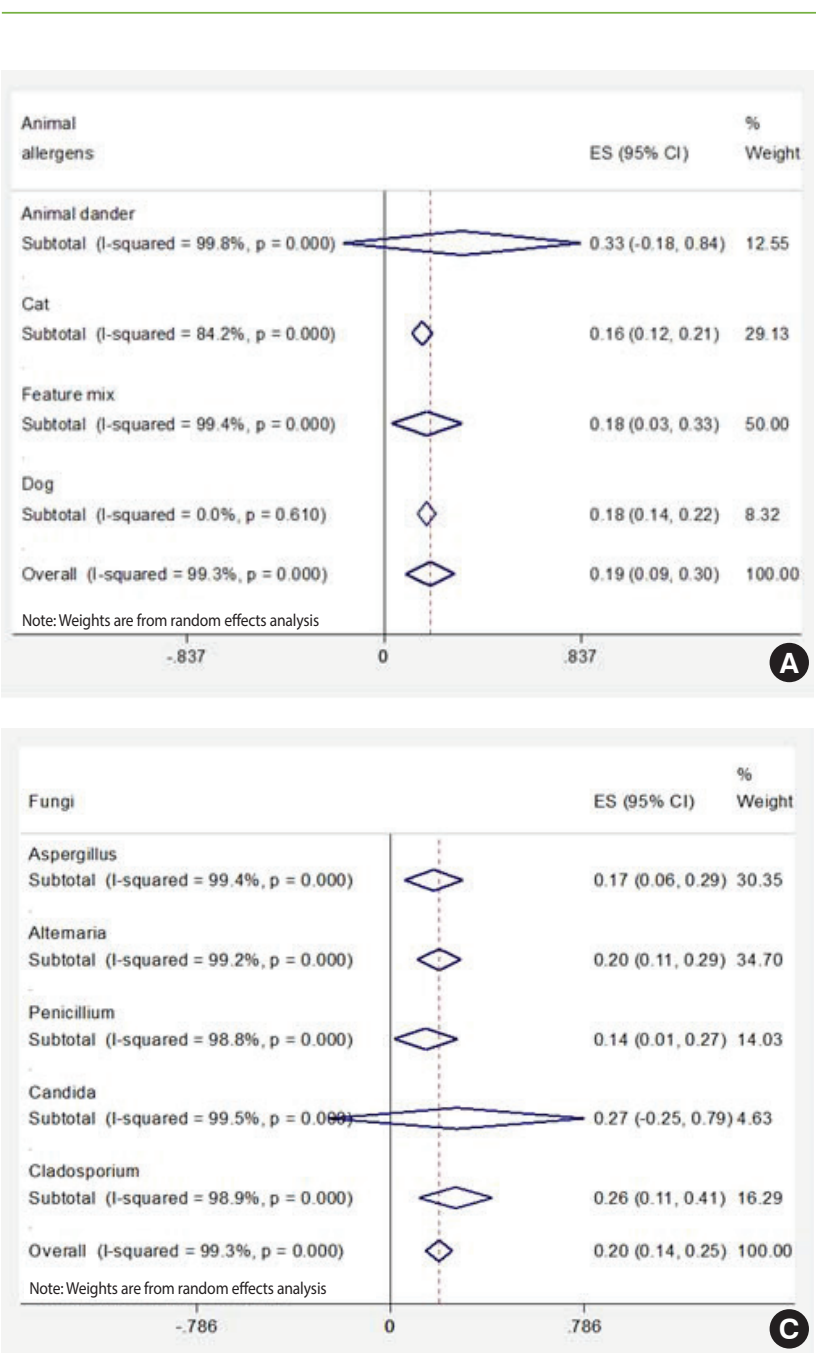

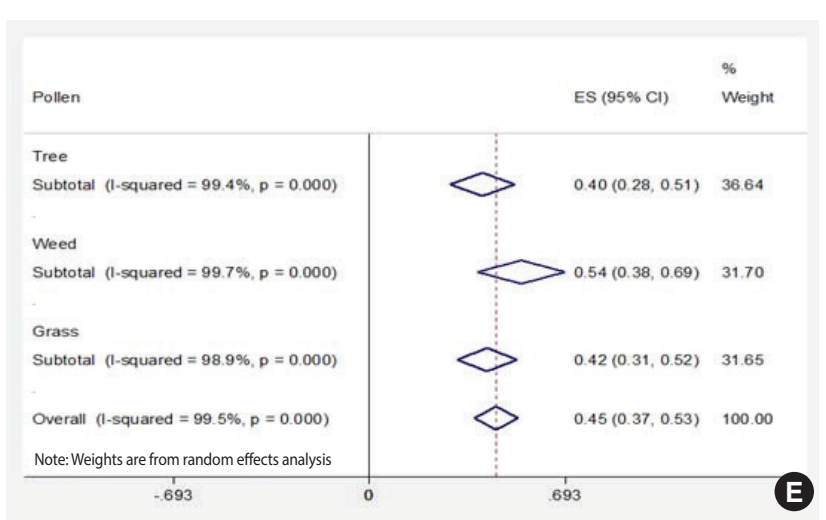

\section{DISCUSSION}

An allergy is defined as an allergen-specific hypersensitivity disease. We estimated the prevalence of six common types of allergens, including those of animals, cockroaches, foods, fungi, HDMs, and pollens in patients with allergies in major cities of Iran. The estimated prevalence of sensitization to at least one of these allergens was found to be $59 \%$ among allergic patients, ac-

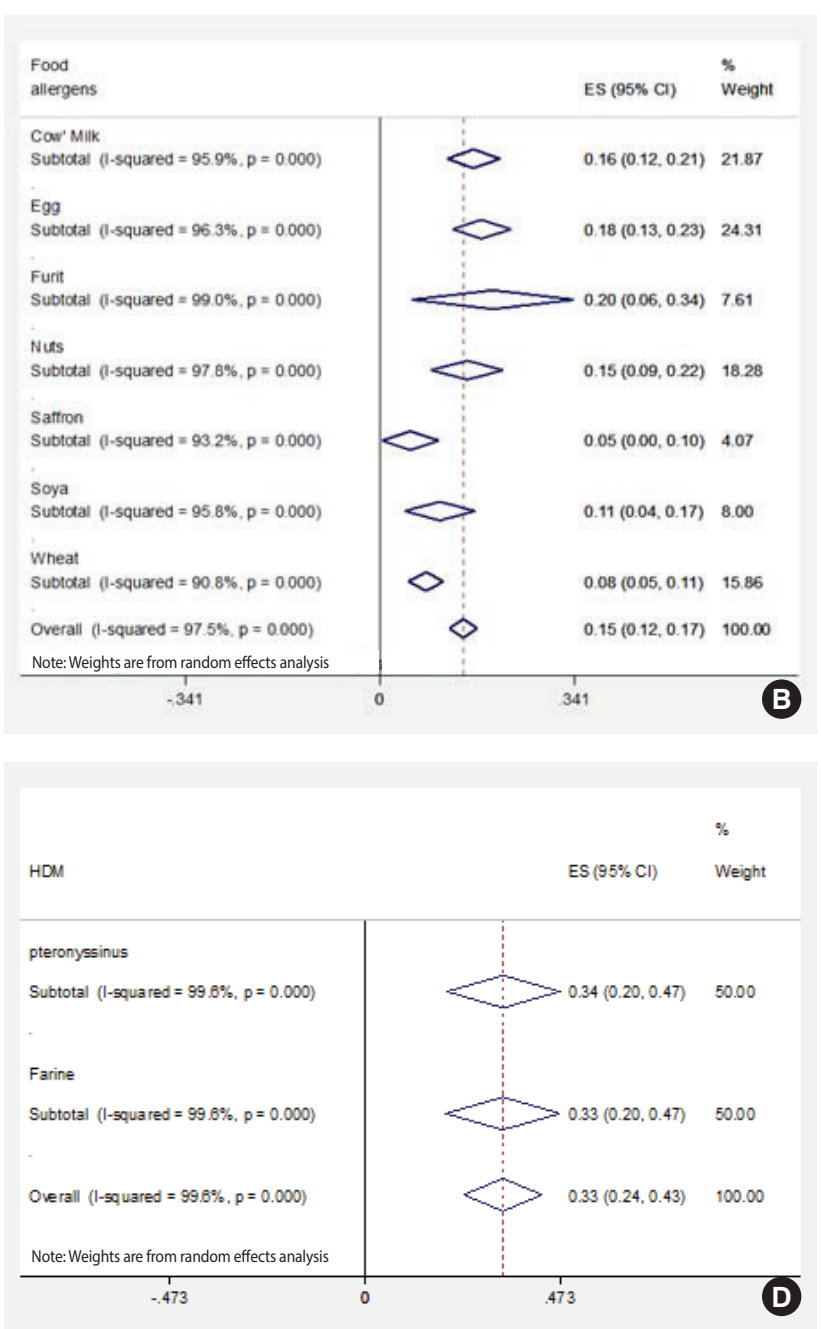

Figure 2. Forest plot of the prevalence of (A) animal, (B) food, (C) fungi, (D) house dust mite (HDM), and (E) pollen allergens sensitization among Iranian patients with allergies. ES, effect size; $\mathrm{Cl}$, confidence interval.

cording to SPT results. However, because of the insufficiency of the data in some cities, such as Isfahan, we could not report the prevalence of sensitization to allergens in Iran in precise detail. Furthermore, not all patients in these selected studies were tested for all the considered allergens.

Our study demonstrated that the prevalence of a positive SPT result in allergy patients in Iran was generally consistent with results found in most neighboring countries. An analysis of SPT re- 
Table 2. Frequency of allergen sensitivity differentiated by type of allergen and major cities of Iran

\begin{tabular}{|c|c|c|c|c|c|c|c|c|}
\hline \multirow{2}{*}{ Allergen types } & \multicolumn{7}{|c|}{ Cites } & \multirow[b]{2}{*}{ All cities } \\
\hline & Tehran & $\begin{array}{l}\text { Mashhad + } \\
\text { Semnan }\end{array}$ & $\begin{array}{c}\text { Tabriz + Zanjan } \\
\text { + Qazvin }\end{array}$ & Shiraz & Ahvaz & $\begin{array}{l}\text { Coastal } \\
\text { areas }^{1}\end{array}$ & $\begin{array}{c}\text { Kerman + Yazd } \\
+ \text { Isfahan }\end{array}$ & \\
\hline \multirow[t]{2}{*}{ Cockroach } & 23.9 & 13.7 & 25.3 & 32.2 & 32.0 & 15.7 & 16.0 & 25.1 \\
\hline & $(19.2,28.6)$ & $(3.7,28.8)$ & $(4.8,45.8)$ & $(24.4,0.0)$ & $(28.6,35.5)$ & $(7.7,23.7)$ & $(10.6,21.4)$ & $(20.1,30.2)$ \\
\hline \multirow{2}{*}{ Food } & 4.9 & 5.1 & 3.1 & 4.2 & TFS & 4.0 & 3.6 & 14.6 \\
\hline & $(2.6,7.2)$ & $(3.2,7.0)$ & $(9.0,7.2)$ & $(4.0,68.0)$ & & $(3.2,4.8)$ & $(0.8,7.9)$ & $(12.2,17.0)$ \\
\hline \multirow[t]{2}{*}{ Fungi } & 40.0 & 3.2 & 9.4 & 10.3 & 13.1 & 33.5 & TFS & 19.6 \\
\hline & $(13.5,66.4)$ & $(16.4,52.2)$ & $(6.0,18.2)$ & $(1.8,18.7)$ & $(3.0,23.3)$ & $(26.0,39.8)$ & & $(14.2,25.0)$ \\
\hline \multirow[t]{2}{*}{ Pollen } & 44.5 & 55.0 & 32.5 & 48.1 & 83.1 & 35.1 & 25.1 & 44.8 \\
\hline & $(23.6,65.3)$ & $(7.8,65.4)$ & $(28.0,37.0)$ & $(22.2,74.1)$ & $(79.0,86.7)$ & $(4.8,65.4)$ & $(7.2,52.0)$ & $(37.1,52.5)$ \\
\hline \multirow[t]{2}{*}{ Animal } & 13.7 & 9.0 & 14.5 & 15.5 & TFS & 48.1 & 5.4 & 19.5 \\
\hline & $(8.9,18.8)$ & $(4.1,13.9)$ & $(10.7,18.4)$ & $(13.2,17.9)$ & & $(18.0,78.2)$ & $(1.9,8.9)$ & $(9.1,29.9)$ \\
\hline \multirow[t]{2}{*}{ HDM } & 34.1 & 17.5 & 16.1 & 25.3 & 40.8 & 63.2 & 16.7 & 33.4 \\
\hline & $(13.4,548)$ & $(13.9,21.0)$ & $(9.8,22.4)$ & $(10.8,39.8)$ & $(26.3,55.3)$ & $(40.3,86.1)$ & $(7.3,37.1)$ & $(24.0,43.0)$ \\
\hline
\end{tabular}

Values are presented as prevalence $\%$ ( $95 \%$ confidence interval).

TFS, too few studies; HDM, house dust mite.

${ }^{1}$ The coastal areas were defined as Babol, Bushehr, Sari, and Zahedan.

Table 3. The prevalence of allergens according to allergen type and age group

\begin{tabular}{|c|c|c|c|c|c|c|c|}
\hline \multirow{2}{*}{ Allergens } & \multirow{2}{*}{$\begin{array}{l}\text { No. of } \\
\text { studies }\end{array}$} & \multicolumn{3}{|c|}{ Prevalence \% (95\% Cl) } & \multicolumn{3}{|c|}{ Q-test } \\
\hline & & $<5 \mathrm{yr}$ & $5-16 \mathrm{yr}$ & $>16 \mathrm{yr}$ & Value & I-square (\%) & $\mathrm{p}$-value \\
\hline Animal & 14 & TFS & $8.4(4.6,12.2)$ & $35.8(15.0,56.7)$ & 3.0 & 99.6 & 0.002 \\
\hline Cockroach & 16 & TFS & $7.1(6.1,8.0)$ & $3.2(2.5,3.9)$ & 40.7 & 94.4 & $<0.001$ \\
\hline Food & 21 & $26.2(22.8,29.7)$ & $11.3(9.8,12.9)$ & $2.8(2.1,3.5)$ & 265.8 & 95.8 & $<0.001$ \\
\hline Fungi & 15 & TFS & $4.2(3.3,5.1)$ & $5.3(4.6,6.0)$ & 3.3 & 78.3 & 0.07 \\
\hline HDM & 23 & TFS & $5.2(4.4,6.0)$ & $8.1(7.4,8.8)$ & 4.3 & 93.2 & $<0.001$ \\
\hline Pollen & 21 & TFS & $3.7(3.0,4.4)$ & $8.4(7.7,9.1)$ & 85.7 & 98.3 & $<0.001$ \\
\hline
\end{tabular}

$\mathrm{Cl}$, confidence interval; TFS, too few studies; HDM, house dust mite.

actions in patients with allergic rhinitis yielded a positive result of 61\% in Turkey [65], 69\% in Pakistan [66], and 75\% in Riyadh [67]. A large difference was observed in positive SPT results among Russian patients, at $21.8 \%$ [68].

Keeping a domesticated dog at home and direct exposure to this animal is very much limited in Iran because of religious beliefs; however, sensitization to animal allergens (cat, dog, and feather allergens in combination) was present in about $20 \%$ of cases among allergic patients. Direct contact with animals may lead to sensitization, but animal allergens can be transferred into environments that were never occupied by the animals [69]. Animal hypersensitivity was detected in $26 \%$ of Turkish patients with allergies, a country that shows a low pet ownership rate similar to Iran [70]. In the current study, the highest prevalence of sensitization to animal allergens was in coastal areas. This difference can be explained by the administration of SPTs with animal dander extract, including a broader type of animal allergens, in a study in Bushehr [35].

The overall prevalence of sensitization to cockroach allergens was $25 \%$ among Iranian patients with allergies. The prevalence of cockroach allergen sensitization was reported to be $12 \%$ in 337 tested children in Turkey [71], 33\% in 151 asthmatic patients in Saudi Arabia [72], and 68.4\% in asthmatic patients in Russia [73]. It seems that sensitization to cockroach allergens is more common among patients with asthma than in other cases of patients with allergies. Positive reactions to cockroach allergens were most frequent in allergic patients living in Ahvaz and Shiraz; this might be accounted for by a high level of cockroach infestation due to the warm climate in southern Iran. Children had more frequent positive results for sensitization to cockroaches; therefore, the application of insecticides and vigorous cleaning of children's bedrooms may be needed to decrease sensitization among children.

Our included studies showed that, according to SPT results, the prevalence of sensitization to food allergens was $15 \%$ overall in patients with allergies. The prevalence of sensitization to food allergens was highest in Australia (83\%) and the UK (74\%). The reason for the lower incidence of food sensitization in Iranians may be the variation in their genetic background. A lower prevalence of food sensitization among adults compared to infants may be a result of a natural increase in tolerance with increasing age $[74,75]$. 
The most common sources of food allergens were eggs (18\%) and cow's milk (16\%), followed by nuts (15\%) and wheat (8\%); this frequency is in accord with what has been found in other studies $[76,77]$. It is noteworthy that the specificity of the SPT is generally low for food allergens, partly because of enzymatic degradation of food proteins during the preparation of extracts, as well as crossreactions between some food groups [19]. Saffron, a spice which is mostly cultivated in Iran, resulted in an immediate positive skin reaction in $70 \%$ of the patients in the study of Varasteh et al. [64]. No significant difference in the sensitization to food allergens was found among major cities of Iran.

The prevalence of sensitivity to various fungal allergens was reported to be from 5 to $20 \%$ in Iranian patients with allergies [78]. There are two reports on the prevalence of allergies to Candida in Iran: one reported a $0.7 \%$ prevalence in patients with rhinitis in Shiraz, and the other reported a $53 \%$ prevalence in patients with eczema and asthma in Tehran $[41,44]$. Candida is a commensal normal flora of the skin, the gastrointestinal tract, and the genitourinary system, although the significance of Candida in allergies is still controversial in the literature [79]; meanwhile, cross-reactivity to other fungal allergens should be considered [80]. Sensitization to other fungal allergens, including Cladosporium, Alternaria, Aspergillus, and Penicillium, was highest in Tehran and coastal areas because of the climate conditions.

The prevalence of sensitization to HDM allergens in Iranian patients with allergies was $33 \%$ in this study. The prevalence of positive results for sensitization to HDMs in neighboring countries has been reported as $25 \%$ in Turkey [81], $46 \%$ in the United Arab Emirates [82], and 67\% in Russia [83]. The prevalence of sensitization to mites in patients with allergies living at sea level was higher than in those living in the high altitude areas of Iran, because mites grow better in environments of higher humidity [84].

In Iranian patients, the most common positive SPT result for allergen sensitization was for allergens from weed, grass, and tree pollen $(45 \%)$ in all cities except coastal areas. Recent studies have shown the impact of climate change on aeroallergen acculturation, as global warming increases pollen production by plants and the allergenicity of pollens, lengthens the production period, broadens the distribution of pollens, and induces changes in plant biomass $[85,86]$. The results of subgroup analysis showed that the prevalence of sensitization to pollens was higher in southwestern Iran, including Ahvaz and Shiraz, than in other regions of Iran. Southwest Iran has a dry and hot climate with short winters, resulting in an increase in the production period and distribution of pollens. In recent years, the effects of storms in the Middle East have become a problematic phenomenon for allergic diseases in southern provinces of Iran [87].

There are other allergens from diverse sources associated with allergic disease. Latex products are occupationally associated aeroallergens, with the clinical significance of this allergen varying according to patient subgroups. The prevalence of sensitization to latex allergen in Iran was reported from 18 to $38 \%$ in health care personnel [88-90], and no sensitization was observed in workers in latex glove factories [91].

There has been no report of the prevalence of insect-sting allergies or their mortality in Iran. Bemanian et al. [92] suggested a relatively fast and safe protocol for venom immunotherapy in 10 patients with systemic reaction to honeybee or yellow jacket bee stings.

No significant publication bias was observed among published studies; both studies reporting low prevalence and high prevalence were included in this meta-analysis.

A positive skin test is not sufficient to confirm the presence of an allergic disease; however, it shows allergic sensitization, which necessitates the evaluation of clinical symptoms, and it also may predict the subsequent onset of allergic symptoms [86]. One of the sources of heterogeneity among allergens may have been differences in the age range of patients who were enrolled in the different studies included in this meta-analysis. The published data were insufficient for consideration of poly-sensitization to diverse allergens.

\section{CONCLUSION}

This study estimated the reported prevalence of sensitization to at least one of the considered allergens to be $59 \%$ based on SPT results. In most parts of Iran, where the climate is hot and dry, pollens were the most common type of allergen, whereas sensitization to mites was most common in northern and southern coastal areas of Iran. This study will help in selecting panels of the most common allergens for SPTs and will also help in finding the best species of allergens for immunotherapy in this area.

\section{CONFLICT OF INTEREST}

The authors have no conflicts of interest to declare for this study.

\section{ORCID}

Mozhgan Moghtaderi: http://orcid.org/0000-0002-9612-2429; Saeed Hosseini Teshnizi: http://orcid.org/0000-0002-5575-6855

\section{REFERENCES}

1. Mari A. When does a protein become an allergen? Searching for a dynamic definition based on most advanced technology tools. Clin Exp Allergy 2008;38:1089-1094.

2. Bergmann KC, Ring J. History of allergy. Basel: Karger AG; 2014, 172-192.

3. Radauer C, Bublin M, Wagner S, Mari A, Breiteneder H. Allergens are distributed into few protein families and possess a restricted number of biochemical functions. J Allergy Clin Immunol 2008; 121:847-852.e7.

4. Ring J, Akdis C, Behrendt H, Lauener RP, Schäppi G, Akdis M, et al. Davos declaration: allergy as a global problem. Allergy 2012; 67:141-143. 
5. Chapman MD, Wood RA. The role and remediation of animal allergens in allergic diseases. J Allergy Clin Immunol 2001;107: S414-S421.

6. Zahradnik E, Raulf M. Animal allergens and their presence in the environment. Front Immunol 2014;5:76.

7. Moghtaderi M, Farjadian S, Abbaszadeh Hasiri M. Animal allergen sensitization in veterinarians and laboratory animal workers. Occup Med (Lond) 2014;64:516-520.

8. Do DC, Zhao Y, Gao P. Cockroach allergen exposure and risk of asthma. Allergy 2016;71:463-474.

9. Moghtaderi M, Farjadian S, Fereidouni M, Nasiri M, Nejat A. Indoor dust allergen levels in the homes of patients with childhood asthma: an experience from Southwestern Iran. Iran J Allergy Asthma Immunol 2016;15:132-137.

10. Patel S, Meher BR. A review on emerging frontiers of house dust mite and cockroach allergy research. Allergol Immunopathol (Madr) 2016;44:580-593.

11. Peat JK, Tovey E, Toelle BG, Haby MM, Gray EJ, Mahmic A, et al. House dust mite allergens. A major risk factor for childhood asthma in Australia. Am J Respir Crit Care Med 1996;153:141146.

12. Allen KJ, Koplin JJ. The epidemiology of IgE-mediated food allergy and anaphylaxis. Immunol Allergy Clin North Am 2012; 32:35-50.

13. Hassan AK, Venkatesh YP. An overview of fruit allergy and the causative allergens. Eur Ann Allergy Clin Immunol 2015;47:180187.

14. Fukutomi Y, Taniguchi M. Sensitization to fungal allergens: resolved and unresolved issues. Allergol Int 2015;64:321-331.

15. Vermani M, Vijayan VK, Agarwal MK. Identification of Aspergillus (A. flavus and A. niger) allergens and heterogeneity of allergic patients' IgE response. Iran J Allergy Asthma Immunol 2015; 14:361-369.

16. Mothes N, Valenta R. Biology of tree pollen allergens. Curr Allergy Asthma Rep 2004;4:384-390.

17. Stemeseder T, Hemmer W, Hawranek T, Gadermaier G. Marker allergens of weed pollen-basic considerations and diagnostic benefits in the clinical routine: Part 16 of the Series Molecular Allergology. Allergo J Int 2014;23:274-280.

18. Andersson K, Lidholm J. Characteristics and immunobiology of grass pollen allergens. Int Arch Allergy Immunol 2003;130:87107.

19. Chiriac AM, Bousquet J, Demoly P. In vivo methods for the study and diagnosis of allergy. In: Adkinson NF, Bochner BS, Burks W, Busse WW, Holgate ST, Lemanske RF, et al. Middleton's allergy: principles and practice. 8th ed. Philadelphia: Mosby Elsevier; 2013, p. 1119-1129.

20. Moher D, Liberati A, Tetzlaff J, Altman DG; PRISMA Group. Preferred reporting items for systematic reviews and meta-analyses: the PRISMA statement. BMJ 2009;339:b2535.

21. Abdollahi-Fakhim S, Sadegi-Shabestari M, Mousavi-Agdas M, Naghavi-Behzad M, Alikhah H. Medical treatment of allergy in children with recurrent or chronic sinusitis. Niger Med J 2014;55:
474-479.

22. Ahanchian H, Jafari S, Behmanesh F, Haghi NM, Nakhaei AA, Kiani MA, et al. Epidemiological survey of pediatric food allergy in Mashhad in Northeast Iran. Electron Physician 2016;8:17271732

23. Ahmadiafshar A, Sepehri S, Moosavinasan SN, Torabi SZ. Recognition and frequency determination of common allergens in allergic patients of Zanjan city by skin prick test. J Zanjan Univ Med Sci 2008;16:45-53.

24. Akbari Hedayat A, Re zaei A. Common allergens for allergic patients in Isfahan: a clinically-based study. J Res Med Sci 2000;5: 68-77.

25. Mokhtari Amirmajdi M, Mokhtari Amirmajdi NA, Eftekharzadeh Mashhadi I, Jabari Azad F, Tavakol Afshari J, Shakeri MT. Alternaria in patients with allergic rhinitis. Iran J Allergy Asthma Immunol 2011;10:221-226.

26. Arshi S, Zarrinfard R, Poorsattar A, Fereshtehnejad SM, Javahertarash N. Prick test: a survey and comparison between Iranian allergic children and adults. Allergol Immunopathol (Madr) 2010; 38:287-290.

27. Assarehzadegan MA, Shakurnia A, Amini A. The most common aeroallergens in a tropical region in Southwestern Iran. World Allergy Organ J 2013;6:7.

28. Behmanesh F, Shoja M, Khajedaluee M. Prevalence of aeroallergens in childhood asthma in Mashhad. Maced J Med Sci 2010;3: 295-298.

29. Bemanian MH, Alizadeh Korkinejad N, Shirkhoda S, Nabavi M, Pourpak Z. Assessment of sensitization to insect aeroallergens among patients with allergic rhinitis in Yazd City, Iran. Iran J Allergy Asthma Immunol 2012;11:253-258.

30. Bonyadi MR, Azarshin N, Baybordi B, Elmiye A. Frequency of mold allergens in allergic rhinitis patients. Med Lab J 2014;8:77-81 (Persian).

31. Farajzadeh S, Bazargan N, Shahesmaeili A, Shahrbabaki AG, Fekri AR. Evaluation of the frequency of food allergens by skin prick test in children with atopic dermatitis. Iran J Dermatol 2010;13: 33-36.

32. Farhoudi A, Pourpak Z, Mesdaghi M, Chavoshzadeh Z, Kazemnejad A. The study of cockroach allergy in Iranian children with asthma. Iran J Med Sci 2002;27:156-160.

33. Farhoudi A, Razavi A, Chavoshzadeh Z, Heidarzadeh M, Bemanian MH, Nabavi M. Descriptive study of 226 patients with allergic rhinitis and asthma in Karaj city. Iran J Allergy Asthma Immunol 2005;4:99-101.

34. Farjadian S, Moghtaderi M, Kashef S, Alyasin S. Sensitization to food allergens in Iranian children with mild to moderate persistent asthma. World J Pediatr 2012;8:317-320.

35. Farrokhi S, Gheybi MK, Movahed A, Tahmasebi R, Iranpour D, Fatemi A, et al. Common aeroallergens in patients with asthma and allergic rhinitis living in southwestern part of Iran: based on skin prick test reactivity. Iran J Allergy Asthma Immunol 2015; 14:133-138.

36. Fazlollahi MR, Pourpak Z, Yeganeh M, Kardor GH, Kazemnejad 
A, Movahedi M, et al. Sesame seed allergy: clinical manifestations and laboratory investigations. Tehran Univ Med J 2007;65:85-90 (Persian).

37. Fereidouni M, Hossini RF, Azad FJ, Assarehzadegan MA, Varasteh A. Skin prick test reactivity to common aeroallergens among allergic rhinitis patients in Iran. Allergol Immunopathol (Madr) 2009; 37:73-79.

38. Fouladseresht H, Safiri S, Moqaddasi M, Razeghi MS, Bazargan $\mathrm{N}$. Prevalence of food and airborne allergens in allergic patients in Kerman. J Kermanshah Univ Med Sci 2014;18:234-241 (Persian).

39. Ghaffari J. Prevalence of aeroallergens in skin test of asthma, allergic rhinitis, eczema and chronic urticaria patients in Iran. J Mazand Univ Med Sci 2012;22:139-151 (Persian).

40. Hosseini S, Shoormasti RS, Akramian R, Movahedi M, Gharagozlou M, Foroughi N, et al. Skin prick test reactivity to common aero and food allergens among children with allergy. Iran J Med Sci 2014;39:29-35.

41. Kashef S, Kashef MA, Eghtedari F. Prevalence of aeroallergens in allergic rhinitis in Shiraz. Iran J Allergy Asthma Immunol 2003; 2:185-188.

42. Khazaei HA, Hashemi SR, Aghamohammadi A, Farhoudi F, Rezaei N. The study of type 1 allergy prevalence among people of South-East of Iran by skin prick test using common allergens. Iran J Allergy Asthma Immunol 2003;2:165-168.

43. Khazaei HA, Khazaei B, Dashtizadeh GA, Mohammadi M. Cigarette smoking and skin prick test in patients with allergic rhinitis. Int J High Risk Behav Addict 2015;4:e23483.

44. Khosravi AR, Bandghorai AN, Moazzeni M, Shokri H, Mansouri P, Mahmoudi M. Evaluation of Candida albicans allergens reactive with specific IgE in asthma and atopic eczema patients. Mycoses 2009;52:326-333.

45. Mahram M, Barikani A, Nejatian N. The frequency of common allergens in allergic rhinitis among the patients referred to the allergy clinic of Qods Hospital in Qazvin during 2007-2010. J Allergy Ther 2013;4:130.

46. Moghtaderi M, Aleyasin S, Amin R, Kashef S. Skin test reactivity to fungal aeroallergens in asthmatic children in southern Iran. Iran J Pediatr 2010;20:242-243.

47. Moghtaderi M, Farjadian S, Kashef S, Alyasin S, Afrasiabi M, Orooj M. Specific IgE to common food allergens in children with atopic dermatitis. Iran J Immunol 2012;9:32-38.

48. Moghtaderi M, Farjadian S, Reihani I. Sensitization to plant food allergens in patients with asthma. Indian J Allergy Asthma Immunol 2015;29:24-27.

49. Moghtaderi M, Hejrati Z, Kolahi N, Heidari B. Sensitization to aeroallergens in patients with allergic rhinitis, asthma, and atopic dermatitis in Shiraz, Southwestern Iran. Indian J Allergy Asthma Immunol 2015;29:79-83.

50. Moghtaderi M, Farjadian S, Hosseini Z, Eghtedari D. The comparison of sensitization to animal allergens in children and adultonset patients with asthma. Indian J Allergy Asthma Immunol 2015;29:67-71.
51. Mohammadi K, Gharagozlou M, Movahedi M. A single center study of clinical and paraclinical aspects in Iranian patients with allergic rhinitis. Iran J Allergy Asthma Immunol 2008;7:163-167.

52. Mohammadzadeh I, Ranjbar B, Alizadeh Navaei R, Aziznejad P. Mite sensitivity in children with allergy. J Babol Univ Med Sci 2012; 14:78-82 (Persian).

53. Movahedi M, Moin M, Farhoudi A. A comparison between diagnostic clinical tests and herbal geography in allergic patients in Tehran and Karaj cities. Iran J Allergy Asthma Immunol 2000;1: 29-31.

54. Nabavi M, Ghorbani R, Nabavi M, Hoseinzadeh Y. Prevalence of food allergy in asthmatic children under 18 years of age in Semnan-Iran in 2007-2008. Faslnamahi Kumish 2010;11:162-168 (Persian).

55. Nabavi M, Ghorbani R, Farzam V. Prevalence of mold allergy in asthmatic patients of less than 18 years old in Semnan. J Kerman Univ Med Sci 2010;17:328-336 (Persian).

56. Nabavizadeh SH, Yazdanpanah SH, Abidi H, Zoladl M. The incidence of common allergens in patients with allergic rhinitis referred to Shahid Mofatteh Clinic, Yasuj, Iran. Armaghane Danesh J 2013;18:736-745 (Persian).

57. Onsori F, Ahmadi A, Mansori M, Khorshidi SM, Pazoki N, Salimian J. Prevalence of food allergens in patients with atopic dermatitis referring to the asthma and allergy clinic in Tehran in 2014. Sci J Kurdistan Univ Med Sci 2016;21:40-46 (Persian).

58. Pourpak Z, Farhoudi A, Arshi S, Movahedi M, Gharegozlou M, Yazdani F, et al. Common food allergens in Iranian children. Iran J Med Sci 2003;28:17-22 (Persian).

59. Pourpak Z, Farhoudi A, Mahmoudi M, Movahedi M, Ghargozlou M, Kazemnejad A, et al. The role of cow milk allergy in increasing the severity of atopic dermatitis. Immunol Invest 2004;33:69-79.

60. Safari M, Amin R, Kashef S, Aleyasin S, Ayatollahi M. Cockroach sensitivity in Iranian asthmatic children under the age of five years. Turk Thorac J 2009;10:26-30. .

61. Salehi T, Pourpak Z, Karkon S, Shoormasti RS, Sabzevari SK, Movahedi M, et al. The study of egg allergy in children with atopic dermatitis. World Allergy Organ J 2009;2:123-127.

62. Shakurnia A, Assarehzadegan MA, Mozaffari AR, Khodadadi A, Amini A, Shakerinejad G, et al. Prevalence of aeroallergens sensitivity in asthmatic patients from Ahvaz. Jentashapir J Health Res 2014;5:461-468.

63. Shakurnia A, Assarehzadegan MA, Mozaffari A, Shakerinejad G, Amini A. Mite and cockroach allergy in patients with respiratory allergies a report from Ahvaz. Med J Tabriz Univ Med Sci Health Serv 2013;35:50-55 (Persian).

64. Varasteh AR, Vahedi F, Sankian M, Kaghazian H, Tavallaie S, Abolhassani A, et al. Specific IgG antibodies (total and subclasses) against Saffron pollen: a study of their correlation with specific IgE and immediate skin reactions. Iran J Allergy Asthma Immunol 2007;6:189-195.

65. Aydin S, Hardal U, Atli H. An analysis of skin prick test reactions in allergic rhinitis patients in Istanbul, Turkey. Asian Pac J Aller- 
gy Immunol 2009;27:19-25.

66. Ahmed A, Minhas K, Micheal S, Ahmad F. Prevalence of skin test reactivity to aeroallergens in the Pakistani population. Public Health 2011;125:324-326.

67. Almogren A. Airway allergy and skin reactivity to aeroallergens in Riyadh. Saudi Med J 2009;30:392-396.

68. Vartiainen E, Petäys T, Haahtela T, Jousilahti P, Pekkanen J. Allergic diseases, skin prick test responses, and IgE levels in North Karelia, Finland, and the Republic of Karelia, Russia. J Allergy Clin Immunol 2002;109:643-648.

69. Zahradnik E, Raulf M. Animal allergens and their presence in the environment. Front Immunol 2014;5:76.

70. Mungan D, Celik G, Bavbek S, Misirligil Z. Pet allergy: how important for Turkey where there is a low pet ownership rate. Allergy Asthma Proc 2003;24:137-142.

71. Yilmaz A, Tuncer A, Sekerel BE, Adalioğlu G, Saraçlar Y. Cockroach allergy in a group of Turkish children with respiratory allergies. Turk J Pediatr 2004;46:344-349.

72. Koshak EA. Skin test reactivity to indoor allergens correlates with asthma severity in Jeddah, Saudi Arabia. Allergy Asthma Clin Immunol 2006;2:11-19.

73. Berzhets BM, Petrova NS, Barashkina OF, Efremenko II, Dotsenko EA, Prishchepa IM. Role of cockroaches Blatella germanica in the development of atopic bronchial asthma. Zh Mikrobiol Epidemiol Immunobiol 2001:43-46 (Russian).

74. de Benedictis FM, Franceschini F, Hill D, Naspitz C, Simons FE, Wahn U, et al. The allergic sensitization in infants with atopic eczema from different countries. Allergy 2009;64:295-303.

75. Alduraywish SA, Lodge CJ, Vicendese D, Lowe AJ, Erbas B, Matheson $\mathrm{MC}$, et al. Sensitization to milk, egg and peanut from birth to 18 years: a longitudinal study of a cohort at risk of allergic disease. Pediatr Allergy Immunol 2016;27:83-91.

76. Yavuz ST, Sahiner UM, Buyuktiryaki B, Soyer OU, Tuncer A, Sekerel BE, et al. Phenotypes of IgE-mediated food allergy in Turkish children. Allergy Asthma Proc 2011;32:47-55.

77. Eigenmann PA, Calza AM. Diagnosis of IgE-mediated food allergy among Swiss children with atopic dermatitis. Pediatr Allergy Immunol 2000;11:95-100.

78. Twaroch TE, Curin M, Valenta R, Swoboda I. Mold allergens in respiratory allergy: from structure to therapy. Allergy Asthma Immunol Res 2015;7:205-220.

79. Fukutomi Y, Taniguchi M. Sensitization to fungal allergens: resolved and unresolved issues. Allergol Int 2015;64:321-331.

80. Crameri R, Zeller S, Glaser AG, Vilhelmsson M, Rhyner C. Cross- reactivity among fungal allergens: a clinically relevant phenomenon? Mycoses 2009;52:99-106.

81. Sönmez Tamer G, Calișkan S. Prevalence of house dust mite allergy in cases with atopic disease symptoms in Kocaeli province, Turkey. Mikrobiyol Bul 2009;43:309-312 (Turkish).

82. Hasnain SM, Al-Frayh AR, Subiza JL, Fernández-Caldas E, Casanovas M, Geith T, et al. Sensitization to indigenous pollen and molds and other outdoor and indoor allergens in allergic patients from Saudi Arabia, United Arab Emirates, and Sudan. World Allergy Organ J 2012;5:59-65.

83. Akhapkina IG, Krakhanenkova SN, Mamlenkova EA, Dobronravova EV, Shushpanova EN. Incidence of hypersensitivity to mycotic and mite allergens. Klin Lab Diagn 2009:33-35 (Russian).

84. Peat JK, Tovey E, Toelle BG, Haby MM, Gray EJ, Mahmic A, et al. House dust mite allergens. A major risk factor for childhood asthma in Australia. Am J Respir Crit Care Med 1996;153:141146.

85. Ariano R, Canonica GW, Passalacqua G. Possible role of climate changes in variations in pollen seasons and allergic sensitizations during 27 years. Ann Allergy Asthma Immunol 2010;104:215-222.

86. D’Amato G, Bergmann KC, Cecchi L, Annesi-Maesano I, Sanduzzi A, Liccardi G, et al. Climate change and air pollution: effects on pollen allergy and other allergic respiratory diseases. Allergo J Int 2014;23:17-23.

87. Miri A, Ahmadi H, Ghanbari A, Moghaddamnia A. Dust storms impacts on air pollution and public health under hot and dry climate. Int J Energy Environ 2007;2:101-105.

88. Nabavizadeh SH, Anushiravani A, Amin R. Natural rubber latex hypersensitivity with skin prick test in operating room personnel. Iran J Allergy Asthma Immunol 2009;8:219-220.

89. Miri S, Pourpak Z, Zarinara A, Heidarzade M, Kazemnejad A, Kardar G, et al. Prevalence of type I allergy to natural rubber latex and type IV allergy to latex and rubber additives in operating room staff with glove-related symptoms. Allergy Asthma Proc 2007;28:557-563.

90. Ghasemi IM, Rezaee M, Jonaidi Jafari N, Izadi M. Latex gloves allergy in dental workers, Iran. Pak J Biol Sci 2007;10:1068-1072.

91. Moghtaderi M, Farjadian S, Momeni Z, Najib K. Natural latex sensitization and respiratory function among workers in latex glove factories: a pilot study. J Occup Environ Hyg 2012;9:D183-D185.

92. Bemanian MH, Farhoudi A, Pourpak Z, Gharagozlou M, Movahedi M, Nabavi M, et al. Systemic and local reactions of bee venom immunotherapy in Iran. Iran J Allergy Asthma Immunol 2007; 6:203-206. 